\title{
Plantas medicinais e seus usos pelos sitiantes da Reserva Rio das Pedras, Mangaratiba, RJ, Brasil ${ }^{1}$
}

\author{
Maria Franco Trindade Medeiros ${ }^{2,5}$, Viviane Stern da Fonseca ${ }^{3}$ Regina Helena Potsch Andreata ${ }^{4}$
}

Recebido em 12/11/2002. Aceito em 29/10/2003

\begin{abstract}
RESUMO - (Plantas medicinais e seus usos pelos sitiantes da Reserva Rio das Pedras, Mangaratiba, RJ, Brasil). Os sitiantes que residem na Reserva Rio das Pedras, localizada no município de Mangaratiba, Estado do Rio de Janeiro, têm origem nos meeiros que trabalhavam nas plantações de banana da antiga fazenda Goiabal. Atualmente, esta fazenda corresponde ao Club Méditerranée, na cota próxima ao oceano Atlântico e à Reserva Rio das Pedras, acima da Rodovia Rio/Santos (BR-101), sendo um remanescente de Floresta Ombrófila Densa no Estado. O objetivo deste estudo foi resgatar informações sobre o uso de plantas medicinais pelos sitiantes que ainda residem nesta Reserva. Através de entrevistas estruturadas e semi-estruturadas aplicadas junto à comunidade, pôde-se fazer um levantamento das plantas presentes ao redor das casas dos mesmos. Ao todo foram citadas 36 espécies medicinais, distribuídas em 34 gêneros e 25 famílias. Estas espécies estão relacionadas a 28 usos medicinais, organizados em sete categorias. Predominaram espécies de plantas herbáceas (21 spp.) seguidas das arbustivas (oito spp.) e arbóreas (cinco spp.). Constatou-se que a folha foi a parte mais utilizada e o modo de preparo do remédio foi o decocto. Quantificou-se o número de citações por informante para cada táxon, possibilitando a indicação das espécies mais utilizadas na área, como a erva-de-santa-maria (Chenopodium ambrosioides L.) e a pitanga (Eugenia uniflora L.).
\end{abstract}

Palavras-chave: etnobotânica, plantas medicinais, sitiantes, Reserva Rio das Pedras (RPPN)

\begin{abstract}
Medicinal plants and its uses by the ranchers from the Rio das Pedras Reserve, Mangaratiba, RJ, Brazil). The ranchers who live in Rio das Pedras Reserve, which lies in Mangaratiba County, State of Rio da Janeiro, came from sharecroppers who worked at the banana plantation of the farmer Goiabal farm. Nowadays, that farm corresponds to the Méditerranée Club in the area next to the Atlantic Ocean and to Rio das Pedras Reservation, above the Rio/Santos highway (BR-101), it is a remainder of the Dense Ombrophylous Forest in the State. The aim of this study was to collect information about the use of medicinal plants by the ranchers who still live in that Reservation. A survey of the plants, which could be found in the area surrounding their houses, was done through the use of structured and semi-structured interviews. In all, 36 medicinal vegetal species distributed in 34 genera and in 25 families were mentioned. Those species are related to 28 medicinal uses, organized in seven categories. The herb species ( 21 species) prevailed, followed by shrubs (eight species) and arboreal (five species). The leaf was found to be the part of the plant most used and the mode of preparation of the medicine was the decoction. The number of citations by the informants for each taxon was quantified, making it possible to indicate the worm seed (Chenopodium ambrosioides L.) and pitanga (Eugenia uniflora L.) as the most used species in the area.
\end{abstract}

Key words: ethnobotany, medicinal plants, ranchers, Rio das Pedras Reservation

\section{Introdução}

A Floresta Atlântica, juntamente com a Floresta Amazônica, constituem cerca de $30 \%$ dos remanescentes de florestas tropicais existentes sobre a superfície terrestre, abrigando não somente a maior diversidade biológica do planeta (Mittermeier et al. 1999), como também alta variabilidade genética expressa, por exemplo, nos componentes bioquímicos que as plantas tropicais produzem (Hamann 1991). Na Floresta Atlântica a diversidade de plantas é estimada em 20.000 espécies, das quais mais de 6.000 são consideradas endêmicas (Mittermeier et al. 1999). Atualmente, é uma das formações florestais mais ameaçadas, uma vez que está entre as 25 regiões identificadas mundialmente como hot spot (Lima \& Guedes-Bruni 1996; Begossi et al. 2000)

Em virtude do impacto causado pelo turismo e pelo acelerado processo de industrialização, a flora nativa vem sendo dizimada, assim como a cultura popular, a economia e a organização social de diversas sociedades humanas pelo avanço da cultura moderna (Brito \& Brito 1999). Desde o início da civilização, o homem faz uso das plantas, pela necessidade de sobrevivência,

\footnotetext{
Monografia de Iniciação Científica da primeira Autora

2 Museu Nacional/UFRJ, Bolsa CNPq (IC)/ CAPES (mariaftm@ @otmail.com)

3 Instituto de Pesquisas Jardim Botânico do Rio de Janeiro

4 Universidade Santa Úrsula, ICBA, Bolsa CNPq

5 Autor para correspondência: mariaftm@hotmail.com
} 
levando-o à descoberta de possíveis aplicações terapêuticas de determinadas espécies (Ribeiro 1996).

Os caiçaras, os pequenos produtores e sitiantes são os principais usuários das plantas medicinais da Floresta Atlântica. Trabalhos desenvolvidos em comunidades locais no Estado do Rio de Janeiro podem ser assim destacados: com os caiçaras (Begossi et al. 1993; Guimarães \& Caldas 1993; Oliveira et al. 1994; Guimarães 1996; Fonseca 1998) e em feiras livres (Stalcup 2000). A transmissão oral do conhecimento sobre o uso de plantas por tais sociedades humanas é praticada há gerações. Porém, o processo de aculturação, onde as novas gerações buscam os meios modernos de comunicação, causa a perda desta tão valiosa transmissão oral. Outro fator que se soma a esta perda cultural é a destruição do hábitat natural em que estão inseridas estas sociedades (Brito \& Brito 1999).

As plantas são a identidade de um conjunto de pessoas, refletem o que são, o que pensam e suas relações com a natureza que os cerca. Esta sábia natureza lhes oferece alimentação, remédios, sustento rentável e desfrute da alma. O presente estudo objetivou resgatar o uso de plantas pelos sitiantes da Reserva Rio das Pedras, importante reduto representativo da vegetação de Floresta Atlântica, a partir das espécies medicinais presentes ao redor de suas casas.

\section{Material e métodos}

Área de Estudo - A Reserva Rio das Pedras está situada no Município de Mangaratiba, no oeste do Estado do Rio de Janeiro, na vertente Atlântica da Serra do Mar, junto à Baía de Sepetiba, entre as coordenadas $22^{\circ} 59^{\prime}$ latitude $\mathrm{S} \mathrm{e} 44^{\circ} 05^{\prime}$ longitude W. Consta de 1.360 hectares, o equivalente a $13 \mathrm{~km}^{2}$. O Km 55 da Rodovia BR-101 (Rio/Santos) é a via de acesso à Reserva, que dista da cidade do Rio de Janeiro 110km (Fig. 1).

Apresenta temperatura média anual de $22^{\circ} \mathrm{C}$, temperatura máxima absoluta de $38^{\circ} \mathrm{C}$ e mínima de $12^{\circ} \mathrm{C}$. O maior índice de pluviosidade ocorre entre os meses de dezembro a fevereiro. A principal bacia hidrográfica é a do Rio Grande, rio encaixado em vale com declividade acentuada, superior a $37^{\circ}$. Em relação à altitude as cotas variam de $20 \mathrm{a} 1.100 \mathrm{~m}$ (Souza 1997).

Aspectos Históricos e Sociais - Em 1831, o TenenteCoronel Luiz Fernandes Monteiro, proprietário das fazendas "Batatal" e "Praia Grande", recebeu o título de "Barão do Saí". O Barão faleceu em 1872 na fazenda "Praia Grande", que depois veio a se chamar

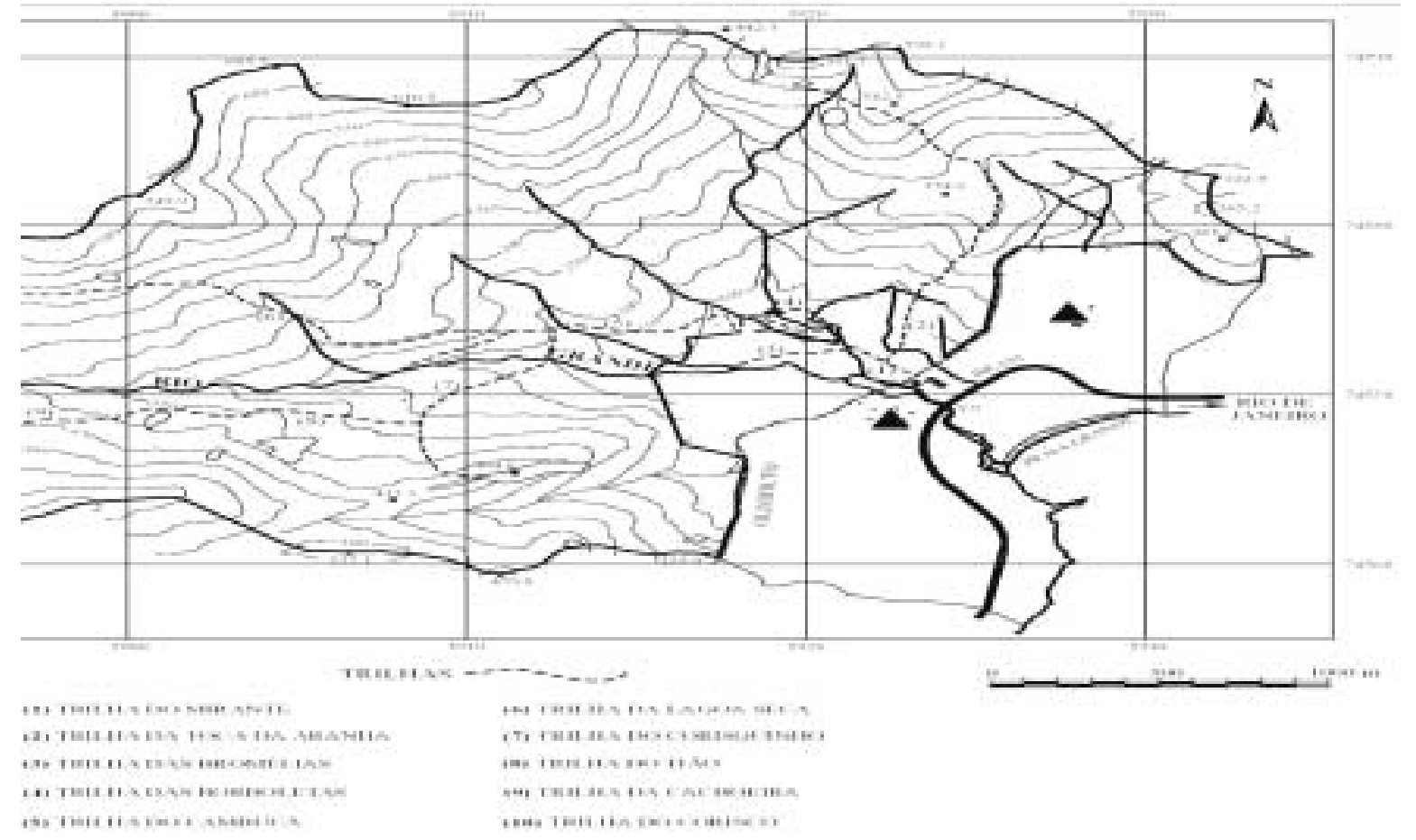

Figura 1. Mapa da Reserva Rio das Pedras, Mangaratiba, RJ. Modificado de Agrofoto Aerofotogrametria S/A (1999). 
"Goiabal", atualmente representada pelo Hotel Club Méditerranée e pela Reserva Rio das Pedras (Fundação Mário Peixoto [198-]).

O porto de Mangaratiba, no passado, era transitado por mercadorias provenientes de diferentes localidades do mundo; em 1914 porém, tornou-se deserto, refletindo os efeitos da construção da estrada de ferro D. Pedro II e Piraense, modificando o aspecto econômico da região (Fundação Mário Peixoto [198-]). Segundo a historiadora Alda Marília Cerqueira de Pinto (com. pess. 2000), foi justamente à época em que a fazenda "Goiabal" chegou às posses de Otacílio Cerqueira. A produção da fazenda era voltada para cultivo e venda de banana. $\mathrm{O}$ carregamento de banana era transportado para barcos com destino ao Rio de Janeiro. Quando da morte do Sr. Otacílio Cerqueira, sua viúva tentou continuar a gestão dos negócios, porém grande parte de sua produção era desviada pelos meeiros, que vendiam diretamente sua colheita. Sendo assim, a única solução para o pagamento das dívidas, contraídas pela manutenção da fazenda e não suprimento de mercadorias, requisitadas pelos compradores de banana do Rio de Janeiro, foi a venda da fazenda para o Club Méditerranée (Club Med) francês, em 1986, para a construção do Village Rio das Pedras, na Praia Grande. Desde então os meeiros, que plantavam banana e davam metade de sua produção ao dono da fazenda como forma de pagamento pela ocupação e utilização de sua terra, tornaram-se sitiantes e vêm sofrendo indenização para que desocupem a área.

Em 1992, o Club Med realizou um acordo com as 14 famílias que residiam no local, para implantar uma Reserva Particular do Patrimônio Natural (RPPN), protegendo a área contra os palmiteiros e caçadores e para desenvolver o ecoturismo (Souza 1997). Algumas dessas pessoas, então, se dirigiram ao Município de Conceição de Jacareí e outras ao Ranchito, bairro da cidade de Mangaratiba. Ainda há nove famílias residindo na área da Reserva, embora existam problemas relativos à posse de terras, gerando conflitos entre os moradores da região.

Os sitiantes da Reserva concentram-se em duas áreas distintas: uma, onde residem seis famílias, cujas casas são estruturalmente compostas por tijolos; e, outra representada por três famílias, com moradias de pau-a-pique. A Figura 1 apresenta a localização aproximada da área onde essas famílias residem, e esta, por ser edificada, ficou na digitalização da figura fora dos limites da Reserva, visando a possibilidade de construções futuras pelo Club Med.
Não existe sistema de esgoto e energia elétrica, sendo a comida preparada em fogão à lenha. Os moradores possuem apenas um rádio de pilha. A água da cachoeira chega até as casas através de canos de $\mathrm{PVC}$, mas o banho continua sendo na própria fonte. $\mathrm{O}$ lixo produzido é por vezes incinerado perto das casas, não havendo local específico para a prática. Os mantimentos básicos como verduras, sal, açúcar, entre outros produtos, são adquiridos nos supermercados de Mangaratiba.

A cultura de banana prata é realizada pelos adultos, que recebem de $\mathrm{R} \$ 3,0$ a $\mathrm{R} \$ 4,0$ por caixa, que é composta por dois a três cachos de banana, e dois deles trabalham na própria Reserva, um como guia e outro como jardineiro. As crianças têm idades entre recém-nascidos e 19 anos, e as mais velhas estudam em Mangaratiba ou em Conceição de Jacareí.

Esforço de campo - Os dados foram obtidos no período de novembro/1999 a agosto/2001. Nesse período foram usadas técnicas de observação participante e técnicas de listagem livre (Kottak 1994) em entrevistas com seis pessoas, duas do sexo masculino e quatro do sexo feminino, que têm conhecimento sobre o uso da flora medicinal representada ao redor de suas casas na Reserva. As entrevistas foram conduzidas de forma estruturada, com perguntas diretas e fechadas; e semiestruturada, com perguntas abertas (Alexiades 1996) e aplicadas a cinco famílias de sitiantes, uma vez que existem nove famílias e 23 pessoas ao todo na região. Os informantes tinham idades que variavam entre 37 e 60 anos de idade. Foram elaboradas fichas de dados para as espécies medicinais, para o informante e para o médico, organizadas segundo modelo proposto por Rios (1996). Realizaram-se visitas ao Hospital Municipal Victor de Souza Breves, em Mangaratiba, a fim de se obter informações do ponto de vista do médico local sobre a comunidade em estudo.

Durante as entrevistas, o material botânico citado como medicinal pelos informantes foi coletado com o prévio consentimento dos mesmos. Através da técnica de listagem livre, onde cada informante, individualmente, citou as dez espécies mais usadas para fins medicinais, foi possível apontar as espécies utilizadas com maior freqüência. Foram obtidas e registradas em fichas as informações sobre o uso medicinal, parte da planta usada e preparado de cada espécie empregada. Junto aos informantes utilizou-se também uma ficha com dados sócio-econômicos que levam a uma caracterização dos diferentes aspectos da comunidade. Ao Diretor e às Assistentes Sociais do Hospital 
Municipal Victor de Souza Breves foram indagadas a freqüência com que os sitiantes se consultam, qual a parte do corpo mais referida, quais os remédios mais indicados e se seguem exatamente o tratamento.

Identificação das espécies e análise dos dados - O material-testemunho foi herborizado e depositado no herbário do ICBA da Universidade Santa Úrsula (RUSU), com duplicatas para o Herbário do Departamento de Botânica do Museu Nacional (R).

A partir da análise dos dados, as plantas foram organizadas em sete categorias de uso medicinal, adaptadas de Ankli et al. (1999), sendo elas: doenças associadas ao aparelho digestivo (APD); doenças associadas ao aparelho respiratório (APR); doenças associadas à condições dermatológicas (CD); doenças associadas à inflamação e dor (IND); doenças associadas ao sistema nervoso (SIN); doenças associadas ao sistema sangüíneo (SIS); doenças associadas a problemas urológicos (UR). Para cada espécie foram quantificados o número de citações, o número total de famílias, gêneros e espécies e organizados segundo a parte da planta usada, uso medicinal e preparado.

\section{Resultados e discussão}

Os sitiantes da Reserva Rio das Pedras fazem uso de grupo diversificado de plantas, presentes ao redor de suas casas, que se encontra distribuído em 36 espécies, 34 gêneros e 25 famílias (Tabela 1). As famílias melhor representadas foram Asteraceae (seis spp.), Lamiaceae (quatro spp.), Araceae (duas spp.), Moraceae (duas spp.) e Rutaceae (duas spp.).

Para as 36 espécies levantadas, obteve-se o total de 64 citações de uso pelos sitiantes. As espécies mais citadas foram erva-de-santa-maria (Chenopodium ambrosioides L.) com cinco citações, seguida de pitanga (Eugenia uniflora L.) com quatro citações, colônia [Alpinia zerumbet (Pers.) Burtt \& Smith], capim-limão [Cymbopogon citratus (DC.) Stapft], saião (Kalanchoe brasiliensis Cambess.) e banana (Musa sapientum L.) com uma citação cada. O hábito predominante das espécies medicinais foi o herbáceo (21 spp.), seguido do arbustivo (oito spp.), arbóreo (cinco spp.), subarbustivo (uma sp.) e trepador (uma sp.), conforme mostra a Tabela 1.

Coe \& Anderson (1999), em estudo etnobotânico realizado na Nicarágua, observaram que a maioria da população pesquisada mantém ao redor de suas casas um jardim, onde crescem espécies alimentícias ou que são utilizadas com fins medicinais, sendo o mesmo procedimento observado nos sitiantes da Reserva Rio das Pedras.

Estar enfermo tem um aspecto humano, orgânico, físico, psicológico e emocional. A partir da técnica de observação participante e do convívio com os sitiantes pôde-se detectar que o conceito de doença, para eles, é qualquer fator intrínseco que impede a realização do trabalho.

Foram relacionadas plantas para 28 usos medicinais. O maior número de espécies citadas foi para o tratamento da gripe (oito spp.), o que concorda com as observações de Amorozo \& Gely (1988) e Rossato (1996), sendo a cura da bronquite o segundo maior grupo (cinco spp.), seguido do efeito calmante (quatro spp.), contra a pressão alta (três spp.), vermes (três spp.), diarréia, dor de cabeça, inflamação e rins (duas spp. cada). Foi citado o uso de uma espécie nas situações de anemia, machucado, coceira no corpo, frieira, furúnculo, verruga, contusão, dor de dente, dor de dente nascendo, dor de estômago, úlcera, hepatite, prisão de ventre, tosse; referido como colírio, cicatrizante, para dor na coluna e fígado, também apenas uma espécie. Relacionando os usos medicinais com o maior número de espécies citadas, foi apontada como a situação de enfermidade mais incidente, pela comunidade, a gripe em crianças, e a pressão alta e a bronquite nos adultos.

No caso das espécies usadas pelos sitiantes no tratamento da bronquite, todas têm efeito sinérgico, segundo o relato dos sitiantes, sendo somente usadas em associação com outras. As plantas medicinais podem ter de um a quatro diferentes usos. A espécie com maior número de usos foi Carica papaya L. (quatro usos), seguida de Cymbopogon citratus, Kalanchoe brasiliensis e Mentha $\times$ villosa Huds. (três usos cada) (Tabela 1).

No preparo de $83 \%$ (31 spp.) dos remédios caseiros utilizam-se as folhas, em seguida $8 \%$ (três spp.) os frutos, e 3\% (uma sp. cada) as raízes, flores e caule. Em relação ao preparado, a decocção (20 spp.) é a forma mais difundida, bem como o xarope (oito spp.), banho e cataplasma (cinco spp. cada), seguidos da forma in natura (quatro spp.), suco (três spp.), bochecho e infusão (uma sp. cada). Em estudos realizados por Coe \& Anderson (1999) na Nicarágua, Ribeiro (1996) e Stalcup (2000) na região Sudeste do Brasil, observa-se também esta mesma incidência na utilização das folhas e do decocto na preparação dos medicamentos.

Cada categoria de uso medicinal abaixo indicada, adaptada de Ankli et al. (1999), bem como os dados 
obtidos, estão apresentados na Tabela 1 .

$\mathrm{Na}$ categoria IND foram inseridas 18 espécies utilizadas para aliviar dores e moléstias infecciosas, como gripes (Tabela 1).

Para a gripe foram indicadas três espécies, utilizadas sob a forma de chá das folhas (decocto), como a pitanga, carqueja e laranja-da-terra. O saião e o hortelã-miúdo associado ao hortelã-grande também são usados no tratamento da gripe, porém, suas folhas são preparadas como xarope. Outro xarope usado na cura da gripe é o composto por flor do mamão, folha da laranja-da-terra, assa-peixe, saião e capim-limão.

Para as dores no corpo em geral foi relatado o emprego da folha do café, na forma de cataplasma amarrado no tornozelo para sanar a dor de cabeça, assim como o decocto do caule da carqueja, para dor de estômago. As flores da macelinha-do-campo, preparadas em infusão e administradas oralmente amenizam, em crianças pequenas, a dor dos dentes quando estão nascendo. A raiz do gervão é usada na forma de bochecho para a dor de dente. Em casos de contusão, indica-se a erva-grossa em forma de cataplasma, onde, as folhas socadas são amarradas com um tecido sobre o local contundido. Para dores de coluna indica-se o banho preparado com as folhas do jaborandi.

Para a cura de inflamação interna costuma-se ingerir o decocto das folhas do algodão e do amor-docampo e para úlcera, utiliza-se o decocto das folhas da espinheira-santa. Como colírio, foi reportada a prática de pingar nos olhos a água do sereno que fica depositada nas folhas da erva-de-santa-luzia, ou então, colocar a folha da planta na água gelada e, com algodão, lavar os olhos.

Na categoria CD são incluídas nove espécies que tratam de problemas como inflamação na cútis, cicatrização de machucados, entre outros problemas de pele (Tabela 1).

As folhas da erva-de-santa-maria, assim como as de saião, são preparadas como cataplasma aplicado diretamente sobre o machucado. Do mesocarpo do fruto do ijuá é feito um cataplasma que é aplicado sobre o furúnculo para curá-lo.

Para a cicatrização do machucado, a população da Reserva utiliza a seiva da banana, que é obtida ao se quebrar um talo da bananeira. Para a cura da frieira, é feito um decocto do pecíolo do inhame, e preparada uma compressa que deve ser colocada morna sobre a mesma. O "leite" (látex) que sai do fruto do mamão, quando colocado sobre a verruga umas duas a três vezes em dias seguidos, faz com que esta caia.

Como anti-séptico usam o banho do decocto das folhas da aroeira e, para a cura de inflamação sobre a derme é feito o decocto das folhas do amor-docampo que purifica a pele pelas substâncias presentes nas folhas. A carobinha é outra espécie também relacionada a tratamentos dermatológicos, o banho com o decocto de suas folhas diminui a coceira no corpo.

$\mathrm{Na}$ categoria APD constam oito espécies usadas para cinco finalidades diferentes (Tabela 1). A cura de vermes nas crianças ocorre através da preparação do suco da erva-de-santa-maria ou do hortelã-miúdo, onde se adiciona leite às folhas trituradas, e toma-se um copo deste pela manhã, bem como o hortelã-grande pela ingestão do decocto de suas folhas. O palmito e a carqueja, preparados na forma de decocção da folha, são administrados no caso de dor de estômago.

Três espécies são empregadas para atuarem nos males do intestino, porém, com diferentes efeitos. A erva-doce e o gervão combatem a diarréia, sendo suas folhas preparadas e ingeridas sob a forma de decocto. A outra espécie relacionada ao intestino é o mamão, que ajuda no problema de prisão de ventre, através da ingestão do fruto maduro.

O picão-da-praia e o boldo são espécies utilizadas contra enfermidades do fígado, a primeira atua no combate à hepatite. Picão e boldo são preparados na forma de decocto da folha e administrados oralmente.

Seis espécies são incluídas na categoria APR e estão relacionadas à rouquidão, tosse e bronquite, doenças comuns na comunidade (Tabela 1 ).

No tratamento da bronquite são utilizadas as folhas da imbaúba-branca, administradas na forma de decocto, ou em associação com as folhas de assapeixe, hortelã-miúdo e a flor do mamão, na forma de xarope. Pode ainda ser feito o suco de saião, que é preparado com o sumo das folhas e leite.

Para o tratamento da tosse, os sitiantes cortam o fruto do limão-galego no sentido de uma cruz, colocam um dente de alho no meio e fervem em água (decocto).

$\mathrm{Na}$ categoria SIS, relacionada às plantas utilizadas para diminuir a pressão alta e em casos de anemia, incluem-se cinco espécies: chuchu, colônia, inhame, erva-cidreira e capim-limão, que são consumidos na forma de decocto de suas folhas, e diminuem a pressão alta, uma das enfermidades comuns na região (Tabela 1). A "batata" (tubérculo) do inhame quando cozida é usada no combate da anemia. Segundo os sitiantes, a "batata" só cozinha em meses de tempo frio. 


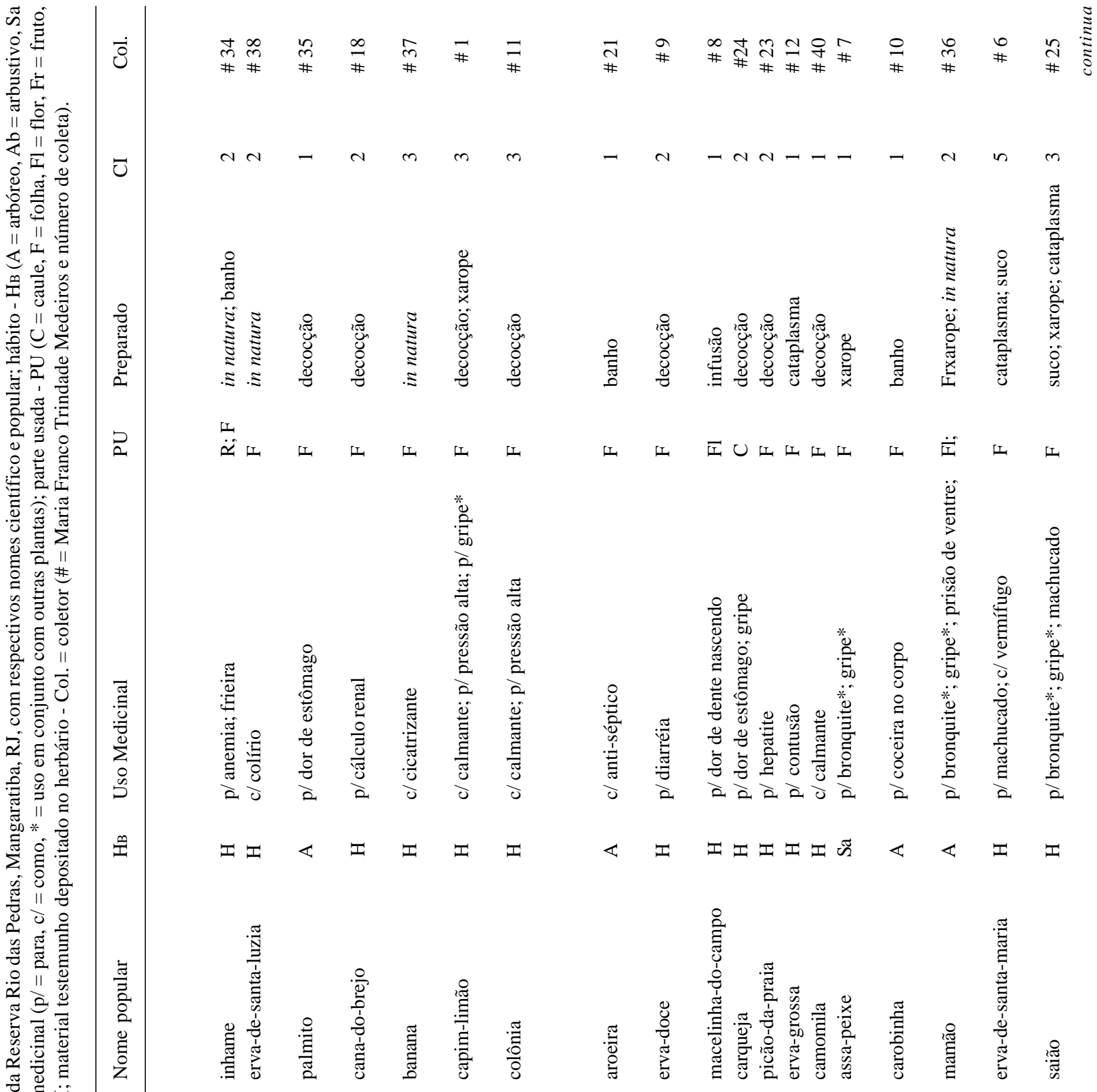

.

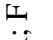




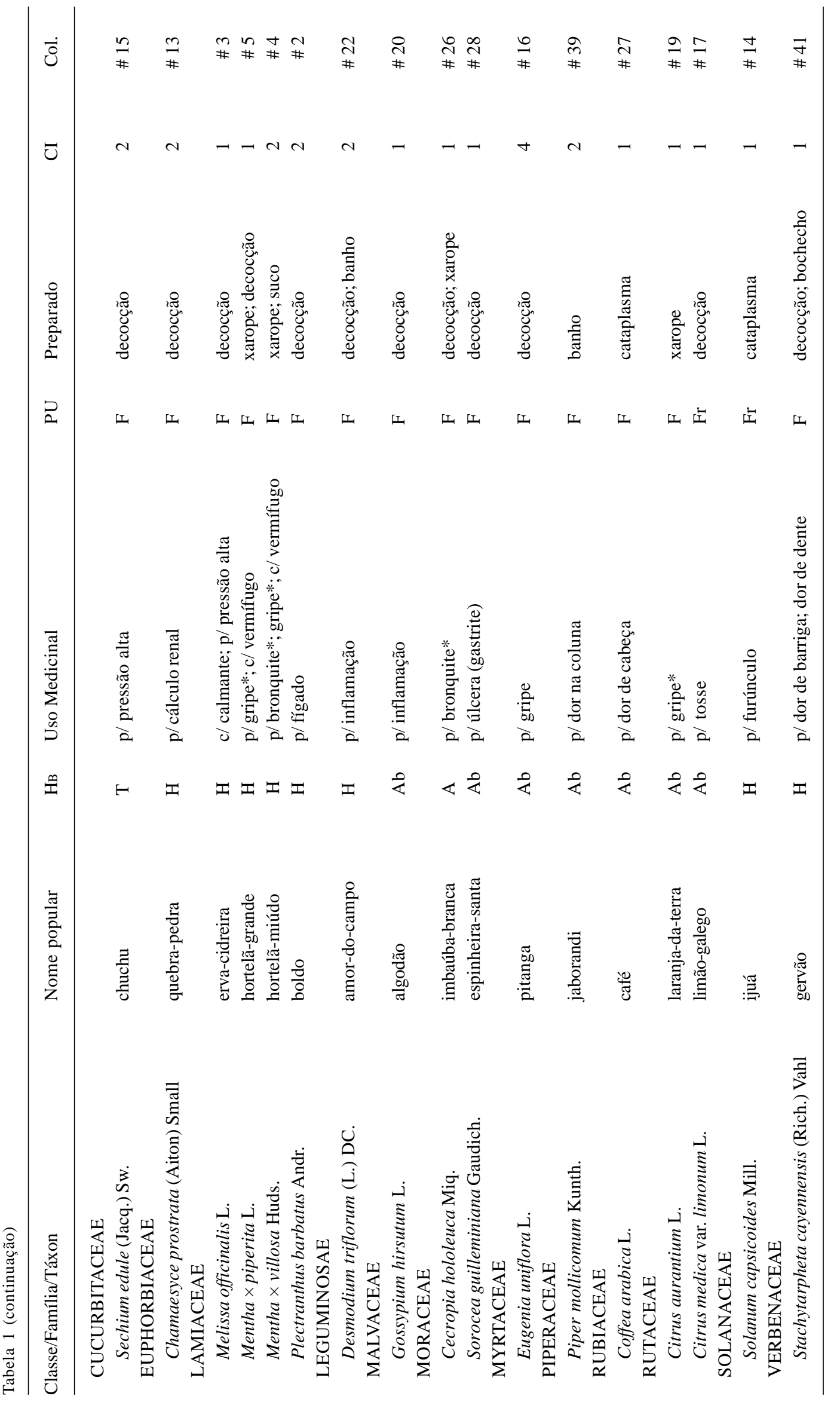


Para a categoria SIN foram indicadas quatro espécies com atividade no sistema nervoso, como calmantes (Tabela 1), foram elas: erva-cidreira, capimlimão, colônia e camomila. Em todas as quatro espécies o medicamento é proveniente das folhas, que são preparadas em decocto, que então é administrado por via oral.

Duas foram as espécies utilizadas para a redução do cálculo renal, incluídas na categoria UR, quebrapedra e cana-do-brejo, sendo suas folhas preparadas em decocto e administradas oralmente (Tabela 1).

A fim de saber mais a respeito da história de vida dos sitiantes foram conduzidas entrevistas com o Diretor e Assistentes Sociais do Hospital Municipal Victor de Souza Breves, em Mangaratiba, único da região. O Diretor, Dr. Bruno Polito, informou sobre a dificuldade enfrentada pelos agentes de saúde, uma vez que a população mostra-se resistente ao tratamento indicado devido à própria cultura da automedicação comum entre os brasileiros e, principalmente, pelo alto custo dos medicamentos alopáticos. Por esta razão, a população prefere seguir o tratamento baseado no conhecimento da medicina tradicional, caseira. Assim, as plantas continuam sendo indispensáveis às terapêuticas na qualidade de matérias-primas para essa comunidade, conforme assinalado por Cunha (1989). Conclui-se, a partir do exposto, que o sistema médico dos sitiantes é um processo histórico vivido pelas pessoas que ali estiveram e pelas que ainda estão, notando-se que os jovens da comunidade não sabem fazer uso do recurso vegetal medicinal disponível, o que também foi observado por Ribeiro (1996) e Begossi et al. (1997).

Com as informações obtidas junto aos sitiantes da Reserva Rio das Pedras, com a complementação de dados científicos, vêm sendo organizado um guia de identificação de plantas medicinais que será encaminhado aos sitiantes, ao Club Méditerranèe, à população de Mangaratiba, através do Hospital Municipal de Mangaratiba, às escolas da cidade, à associação de moradores e aos outros órgãos municipais de Meio Ambiente no Município. Esta proposta fica clara em Alexiades (1996) e Martin (1995), onde o estudo deve beneficiar de alguma forma as pessoas envolvidas, individualmente, ou em comunidade, ou os dois.

Apesar de terem sido citadas espécies já documentadas em outros trabalhos, como o de Amorozo \& Gely (1988), realizado com caboclos do Baixo Amazonas; Berg \& Silva (1988) no Estado de Roraima; Rêgo (1988) na Baixada Maranhense; Ming (1995) na
Reserva Extrativista "Chico Mendes" - Acre; Begossi et al. (1993; 1997; 2000) em áreas de Floresta Atlântica do Estado de São Paulo e Costa-Neto \& Oliveira (2000) no Estado da Bahia, esse estudo buscou contribuir para o conhecimento popular regional de uma comunidade pouco estudada do ponto de vista etnobotânico no Estado do Rio de Janeiro e do uso de espécies em áreas habitadas de Floresta Atlântica.

\section{Agradecimentos}

Os autores agradecem a todos os sitiantes por sua prestimosa colaboração neste estudo; ao Sr. Edílio Gomes da Silva, por sua cordial acolhida; à CAPES e ao Conselho Nacional de Desenvolvimento Científico e Tecnológico ( $\mathrm{CNPq})$, pelas bolsas concedidas.

\section{Referências bibliográficas}

Alexiades, M.N. 1996. Selected guidelines for ethnobotanical research: a field manual. The New York Botanical Garden Press, New York.

Amorozo, M.C.M. \& Gely, A. 1988. Uso de plantas medicinais por caboclos do baixo Amazonas. Barcarena, PA, Brasil. Boletim do Museu Paraense Emílio Goeldi, sér. Bot. 4(1): 47-131.

Ankli, A.; Sticher, O. \& Heinrich, M. 1999. Medical Ethonobotany of the Yucatec Maya: healers consensus as a quantitative criterion. Economic Botany 53(2): 144-160.

Begossi, A.; Leitão-Filho, H.F. \& Richerson, P.J. 1993. Plant uses in a Brazilian fishing community (Búzios Island). Journal of Ethnobiology 13: 233-256.

Begossi, A.; Figueiredo, G.M. \& Leitão-Filho, H.F. 1997. Ethnobotany of Atlantic Forest Coastal Communities: II. Diversity of plant uses at Sepetiba Bay (SE Brazil). Human Ecology 25(2): 353-361.

Begossi, A.; Hanazaki, N.; Tamashiro, J.Y. \& Leitão-Filho, H.F. 2000. Diversity of plant uses in two Caiçara communities from the Atlantic Forest coast, Brazil. Biodiversity and Conservation 9: 597-615.

Berg, M.E. van den \& Silva, M.H.L. 1988. Contribuição ao conhecimento da Flora Medicinal de Roraima. Acta Amazônica 18(1-2): 23-35.

Brito, A.R.M. \& Brito, A.A.S. 1999. Medicinal plant research in Brazil: data from regional and national meetings. Pp. 386-401. In: M.J. Balick; E. Elisabetsky \& S.A. Laird (eds.). Medicinal Resources of the tropical forest biodiversity and its importance to human health. Columbia University Press, New York.

Coe, F.G. \& Anderson, G.J. 1999. Ethnobotany of the Sumu (Ulwa) of Southeastern Nicaragua and comparisons with Miskitu plant lore. Economic Botany 53(4): 364-394. 
Costa-Neto, E.M. \& Oliveira, M.V.M. 2000. The use of medicinal plants in the County of Tanquinho, state of Bahia, Northeastern Brazil. Revista Brasileira de Plantas Medicinais 2(2): 1-6.

Cunha, O. 1989. Ementa da cultura luso-brasileira. Erca, Rio de Janeiro.

Fonseca, V.S. 1998. Etnobotânica da Reserva Ecológica Estadual de Jacarepiá, Saquarema, RJ: um ensaio. Monografia de Bacharelado. Universidade Santa Úrsula, Rio de Janeiro.

Fundação Mário Peixoto [198- ]. Histórico de Mangaratiba. Mangaratiba.

Guimarães, E.M.M. 1996. Estudos etnobotânicos na Restinga de Maricá (RJ). Pp. 371. In: Resumos do XLVII Congresso Nacional de Botânica, Nova Friburgo, RJ. Rio de Janeiro.

Guimarães, E.M.M. \& Caldas, J.F. 1993. Aplicação da teoria do nicho ecológico em uma comunidade humana. Pp. 233-245. In: Resumos do III Simpósio de Ecossistemas da Costa Brasileira. ACIESP.

Hamann, O. 1991. The Joint IUCN-WWF Plants conservation programme and its interest in medicinal plants. Pp. 13-22. In: O. Akerek; V. Heywood \& H. Synge (eds.). The Conservation of Medicinal Plants. Cambridge University Press, Cambridge.

Kottak, C.P. 1994. Antropologia - una exploración de la diversidad humana con temas de la cultura hispana. $6^{\mathrm{a}}$ ed. Madrid, Mc Graw-Hill.

Lima, M.P.M. \& Guedes-Bruni, R.R. 1996. Reserva Ecológica de Macaé de Cima, Nova Friburgo, RJ - Aspectos florísticos das espécies vasculares. v. 2, Jardim Botânico, Rio de Janeiro.
Ming, L.C. 1995. Levantamento de Plantas Medicinais na Reserva Extrativista "Chico Mendes"- Acre. Tese de Doutorado. Universidade Estadual de São Paulo, Botucatu.

Martin, G.J. 1995. Ethnobotany. Chapman \& Hall, London. Mittermeier, R.A.; Myers, N.; Gil, P.R. \& Mittermeier, C.G. 1999. Hotspots. Cemex S.A., Cidade do México.

Oliveira, R.R.; Lima, D.; Sampaio, P.D.; Silva, R.F. \& Toffoli, D.D.G. 1994. Roça Caiçara, um sistema "primitivo" autosustentável. Ciência Hoje 18(104): 44-52.

Rêgo, T.J.A.S. 1988. Levantamento de plantas medicinais na Baixada Maranhense. Acta Amazônica 18(1-2): 75-88.

Ribeiro, L.M.P. 1996. Aspectos Etnobotânicos numa área rural - São João da Cristina, MG. Dissertação de Mestrado. Universidade Federal do Rio de Janeiro/ Museu Nacional, Rio de Janeiro.

Rios, M. 1996. Ficha de datos para plantas medicinales. [S.1.: s.n.].

Rossato, S.C. 1996. Utilização de plantas por populações do litoral norte do Estado de São Paulo. Dissertação de Mestrado. Universidade de São Paulo, São Paulo.

Souza, R. 1997. Ecoturismo em unidade de conservação: estudo de caso da Reserva Rio das Pedras, Mangaratiba, Rio de Janeiro. Dissertação de Mestrado. Universidade Federal Rural do Rio de Janeiro, Rio de Janeiro.

Stalcup, M.M. 2000. Plantas de uso medicinal ou ritual numa feira livre no Rio de Janeiro, Brasil. Dissertação de Mestrado. Universidade Federal do Rio de Janeiro/ Museu Nacional, Rio de Janeiro. 